\title{
Uptake of Screening Mammogram in West-central Illinois During COVID-19 Pandemic: Lessons Learned
}

John Owoade Agboola

Western Illinois University

Oluwasola Stephen Ayosanmi ( $\sim$ osa355@usask.ca )

University of Saskatchewan

Maureen P. Bezold

Western Illinois University

Oluwatobi Mogbojuri

Western Illinois University

Research Article

Keywords:

Posted Date: January 6th, 2022

DOI: https://doi.org/10.21203/rs.3.rs-1157249/v1

License: (c) (i) This work is licensed under a Creative Commons Attribution 4.0 International License. Read Full License 


\section{Abstract}

Objectives. The study aims to reveal the trend of mammogram uptake in seventeen rural counties in Illinois to understand how the COVID-19 pandemic is influencing breast cancer screening in the area.

Methods. Aggregated data on mammography screening for west central Illinois was provided by the Illinois Hospital Association. Data for 2018 and 2019 was used to determine the typical monthly and annual screenings for the two years before the onset of COVID-19. Then, the two years' data was compared to the 2020 data. The monthly mean values for the aggregated 2018 and 2019 data were generated as the base "year" to compare with the monthly value for 2020. Paired T-Test analysis was used to find if there were any statistically significant differences the years and between the base year and 2020.

Results. January 2020 revealed an uptick to 2,921, which is more than the uptake for January 2018 (2700) and January 2019 (2488), and 13\% greater than the mean value of 2,594 for the previous two years. This was followed by a gradual decrease in uptake in February 2020 by $4 \%$ compared to previous years at a mean of 2518 and a further decline in March (44\%), with a drastic fall (98\%) by April 2020 at 56 screening mammograms in all 17 counties. The lowest uptake in any three months occurred from March through May 2020. Compared to previous years, increase in uptake was noted across the region in 2020 June (8\%) and July (4\%) after the pandemic restrictions were relaxed. Overall, the total uptake in 2020 was $15 \%$ less than the average annual uptake for 2018-2019 with a deficit of 5,537. There was no statistically significant difference in mammogram uptake across the three years.

Conclusion. The findings reveal that there was a significant reduction in uptake during the pandemic restriction period. However, increased uptake during the rest of the year effectively mitigated this reduction to such an extent that there was no statistically significant downturn compared to each of the previous two years. A rising trend in total annual uptake noted in preceding years could have continued without the COVID-19 event.

\section{Introduction}

The United States has seen a decline in breast cancer mortality and morbidity over the last four decades (1980-2020). ${ }^{1,2}$ In the same period, the U.S. saw advances in early detection and treatments resulting in less mutilation of patients. ${ }^{3}$ Screening mammography is reported to be responsible for a more than $40 \%$ reduction in mortality because of early breast cancer detection. $4,5,6$

Screening mammogram uptake varies in across regions of the United States and is influenced by race, ethnicity, socioeconomic status, and level of education. ${ }^{7}$ Every decade, since the advent of mammography in the 80 s, there has been an increase in uptake in screening mammograms with better outcomes in breast cancer treatment. This occurs because the survival rate in patients treated for early- 
stage breast cancer is $88-99 \% .{ }^{2,6}$ However, some insurance reforms have reduced the uptake of mammography in the last decade. ${ }^{7,8}$

The current decade began with the onset of the coronavirus disease, COVID19, pandemic, which has interrupted nearly all cancer screening procedures in the United States. ${ }^{9}$ Specifically, between March and May 2020, the lockdown declared by the federal government, ${ }^{10}$ professional organizations, ${ }^{11,12}$ and state governments, ${ }^{13}$ restricted nearly all non-emergency procedures. The restrictions were part of the public health measures to curtail the spread of the virus. ${ }^{14}$

Screening mammography was among the non-emergent procedures put on hold during the lockdown to mitigate COVID-19. ${ }^{15}$ This resulted in a significant reduction in the uptake of screening mammograms during the lockdown period. ${ }^{16-20}$ However, these reports did not consider rural communities in the U.S., nor did they examine how the lifting of lockdown restrictions affected the use of screening mammography. While it seems logical to assume that the lockdown prevented access to mammograms during the three months of lockdown, there is scarce data about what happened regarding screening mammograms the rest of 2020 after the lockdown.

In the state of Illinois, one study reported that limited geographical access to primary health care significantly increases the risk of late diagnosis for persons living outside the city of Chicago. ${ }^{21}$ This finding suggests that, for breast cancer screening and detection, people living in rural communities may be at more a disadvantage than those living in metropolitan areas. However, there is insufficient evidence to understand how the COVID-19 pandemic affected disease detection in both rural and urban communities.

West-central Illinois is one of the regions of the state made up of mostly rural communities. The Illinois Area Health Education Council (IL AHEC) has named west-central Illinois as a target community for the deployment of health care professionals to promote access to comprehensive care. IL AHEC promotes the education and training of health professionals for rural health services. ${ }^{20}$ Presently, there are scant reports about the trend of mammogram uptake in the west-central Illinois region pre-pandemic and let alone during the pandemic.

This study aims to reveal the trend of mammogram uptake in west central Illinois to understand how the COVID-19 pandemic influences breast cancer screening in other rural communities.

\section{Methods}

The study area is west central Illinois. The region has seventeen counties, one of which is designated as urban (Table 1). The total population in the 17 counties is 292,000 people. The people are predominantly white, and the poverty rate is slightly below that of the state of Illinois, which was $11.5 \%$ in $2019 .{ }^{22}$ Five of these counties have no screening mammography center and visit surrounding counties for the procedure. 
We conducted a cross-sectional study of secondary aggregated de-identified data obtained from the Illinois Hospital Association Comp-Data on screening mammogram uptake in the west central region of Illinois. Annual screening mammogram uptake data for 2018 - 2020 was retrieved for the seventeen counties making up the IL AHEC West Central Illinois Region. Essentially, the screening mammograms done each month for 2018, 2019 and 2020 were analysed. First, we reviewed the data for 2018 and 2019 to establish what was typical for the region before the onset of COVID-19. Then, we compared the two years' data to that of 2020 for comparison. For comparison, the average uptake for 2018 and 2019 was calculated and categorized as the base year. The base year value was then compared with that of 2020 , the pandemic year. Finally, the percentage difference per month and year was calculated as the ratio of pandemic year to base year in percentage.

\section{Ethical Consideration}

The Institutional Review Board of Western Illinois University, where the researchers are affiliated, approved a waiver of consent because de-identified secondary data was used for the study.

\section{Data Analysis}

Data analysis was done using Microsoft Excel and IBM SPSS version 27. Essentially, we estimated the average mammogram uptake for 2018, 2019 and 2020. The mean for 2018 and 2019 was identified as the Base year to compare with the mean value for 2020. Paired T-Test analysis was done to check for statistically significant differences between the years of comparison.

\section{Results}

\section{Demographic Characteristics}

The data revealed that eighty-six hospitals served residents of west-central Illinois during the period 20182020. Twenty of the hospitals performed $98 \%$ of total mammograms in the region during the study period (Table 1). Fourteen of these hospitals are found within the region, and six are in the five counties that border the region to the east. Rock Island County accounted for $35 \%$ of the total number of mammograms in the region during the study period. Adams County accounted for $13 \%$ and Knox County for $11 \%$. These three counties account for $58.5 \%$ of the screening mammograms in the region (Table 1 )

\section{The Trend in Annual Screening Mammogram Uptake in West Central Illinois Region}

Table 2 shows the description of the annual screening mammograms in the region from 2019 to 2020. There was an increasing trend in uptake of mammograms from 2018 to 2019. In 2019, 36,307 mammograms were done, an increase of 265 mammograms above that of 2018. However, this rising trend in uptake was interrupted in 2020. As a result, the total annual screening mammogram uptake in 2020 was lower than each of the previous two years, with a total of 30,638 procedures for the year (Table 2). 


\section{Comparing Mammogram Uptake in the Pre-pandemic Years to the Pandemic Year}

The mammogram uptake for 2020 was compared to the mean values for 2018 and 2019, otherwise referred to as the base year. In addition, the percentage difference between 2020 and the base year was calculated. This comparison was done because screening mammogram is mainly performed biannually for the eligible population. Findings show that January 2020 revealed an uptick of 2,921, which was $113 \%$ of the average value of 2594 for January uptake in the previous two years. This was followed by a gradual decrease in uptake in February 2020 (96\%), further decline in March (56\%) with a drastic fall to $2 \%$ by April 2020 with only 56 screening mammograms performed in the whole region. (Figure 1).

The decrease in uptake began in February 2020 (96\%). By the time the restriction on non-emergent procedures was lifted, the accumulated reduction in screening mammogram in the study area peaked by end of May 2020 at 5864. At the end of the year 2020, the deficit compared to previous years was $15 \%$ with 5537 fewer screening mammograms provided (Table 2).

The monthly uptake for screening mammograms during the 36 months ranged from 56 to 3731 (Figure 2). April 2020 had the lowest uptake of 56, while October 2018 had the highest uptake of 3731 . April 2020 was an outlier because the second-lowest uptake was 1491 in May 2020. The lowest uptake in any three months occurred from March through May 2020. The mean monthly uptake in 2018-2020 was 2861, and the median value was 2921 . Therefore, April 2020 had an uptake of $2 \%$ of the monthly mean.

An increase in uptake was noted across the region in June 2020 (108\%) and July (104\%) compared to previous years (Figure 3). This was followed by another positive difference in September (105\%). The rest of the year looked comparatively the same, with a recurrent annual spike in October (Figure 4). The total uptake in the three months of COVID-19 restriction (March to May 2020) was 3195, compared to the total uptake of 8898 and 9021 in March to May 2018 and 2019, respectively. Overall, the total uptake in 2020 was $15 \%$ less than the calculated average annual uptake for 2018-2019. Overall, there was no statistically significant difference in the uptake of mammogram in $2018(M=3003, S D=303)$ vs $2020(M=2553$, SD $=1000)$ and $2019(M=3025, S D=309)$ vs $2020(M=2553, S D=1000), t-1.622, p>0.05$. The eta square statistics $(0.47,0.48)$ show large effect size (Table 3$)$.

The paired sample T-test did not show any statistical difference for the West Central Illinois region screening mammogram uptake in 2020 compared to the previous two years' annual average $(P=0.15)$. In addition, when analysed for each county, there was no statistically significant difference between 2020 and the annual average for the previous two years. In contrast, when analysis of the total count was done for each month in the year 2020 compared with previous years, there was a statistically significant difference in April ( $p=0.013,95 \% \mathrm{Cl} 48.3,298.01)$.

\section{Discussion}

The results reflect changes consistent with the onset of the COVID-19 pandemic that began in early 2020 . For a two-month period lasting from mid-March until mid-May, there was little to no uptake of screening 
mammograms in many West Central Illinois counties. ${ }^{13,14}$ The reduction in uptake from March to May 2020 was significantly different from the previous two years. This same trend had been reported in several other studies. ${ }^{9,15-18}$ However, the overall annual reduction in uptake in 2020 was not statistically significant. This finding could be explained by the increase in mammogram uptake just after the lockdown was lifted.

Many of the reports published in 2020 highlighted the significant reduction in screening uptake during the early months of the pandemic. ${ }^{16-20}$ In April 2020, the Breast Cancer Surveillance Commission reported a $1 \%$ countrywide screening mammography uptake, which is similar to the $2 \%$ found in our study. ${ }^{16}$ The increase in uptake seen in the study region in June and July was due to efforts by the mammogram centers/hospitals to reschedule patients who had missed appointments and to expedite the screening procedure for those who responded positively.

A study by Miller et al. (2021) looked at the likelihood of patients returning for breast cancer screening after COVID-19 related closures. This report noted that people leaving in poverty areas, with lack of health insurance, and where mobile mammograph services were not available were unlikely to return for missed screening schedules. Therefore, the socioeconomic impact of the pandemic in rural west central Illinois, and the lack of mobile imaging services, may account for the remaining deficit at the end of the year. ${ }^{23}$

What is notable is that the increasing trend in the previous two years was interrupted after January 2020, when the uptake rate was higher than the base years. Nevertheless, it is difficult to figure out if the increasing trend in uptake would continue without the COVID-19 pandemic. Presently there is minimal research about the overall impact of COVID19 on screening mammogram uptake in 2020 and efforts to mitigate this from other centers/regions in the USA.

Similarly, the trend of mammogram uptake notably increased in October across the three years due to the annual marking of Breast Cancer Awareness Month. Perhaps if the lockdown was not lifted, the usual, increasing trend might have been interrupted in October 2020. However, it is difficult to predict any likely drop from the available data due to the short duration of the lockdown and paucity of data. The eventual rebound in the uptake of screening mammograms in West Central Illinois post-pandemic lockdown is commendable. Our interactions with mammogram centers in Warren, McDonough, Hancock, and Adams counties confirmed that these centers made definite efforts to reschedule and ensure that available client had their screening procedures done promptly.

The Breast Cancer Surveillance Commission report, which did not account for the entire year, also noted a rebound in mammogram uptake by July 2020 and emphasized the need to make up for deficits. ${ }^{18}$ These reports expressed fears that prolonged postponement of screening procedures might lead to an increase in cancer-related deaths, particularly breast and colon cancer, in the near future.

It is very likely that the increase in uptake in June, July, and September in 2020 reflects the impact of the healthcare institutions' efforts in West Central Illinois to mitigate the impact of the pandemic COVID-19. 
Stimulus payments and guidelines to insurance companies to keep the insurance status of their clients during the year most likely helped too. Our findings show that screening centers in West Central Illinois made efforts to mitigate the impact of the restrictions.

\section{Limitations}

Secondary data analysis comes with some limitations including not being part of the data collection processes. Hence, some additional data that could be important in understanding the pattern and trend of mammograms uptake in this region were unavailable. For example, exploring the methods instated by each mammogram center to mitigate the impact of COVID-19 restrictions on the number of screening mammograms completed at their facility is beyond the scope of this report. However, the Illinois Hospital Network data sufficiently provide bases for comparing the total mammograms uptake before and after the pandemic shutdown.

\section{Public Health Implications}

The COVID-19 pandemic is not a common event. Its occurrence has tested the American healthcare system and brought to the fore the importance of public health. Strengthening systems to ensure the interdependencies of several aspects of healthcare are properly integrated for the benefit of the whole has become clear. It became necessary to prioritize the use of limited resources for the community by triaging individual needs during the peak of the pandemic. Health institutions have shown resilience, and full recovery to pre-pandemic status is expected.

The COVID-19 related delays in cancer screening have been predicted to result in a cumulative one million new cases of breast and colon cancers over the next five years. ${ }^{16}$ Other factors contributing to about a $15 \%$ reduction in mammogram uptake during the pandemic may include unemployment, loss of insurance coverage, and geographical migrations. ${ }^{23}$ These factors need to be explored further.

Recovery will take time, especially with the persistence of COVID-19 caused by the emergence of several variants and complicated by international travels. While we continue to prioritize case management and vaccination of the populace, we should put more effort into promoting cancer screening even beyond the pre-pandemic era. This action is important because to reach pre-pandemic levels in cancer screening uptakes and sustain a rising trend to achieve the Healthy People 2030 targets requires concerted strategies. Prompt action at this time may mitigate the morbidity and mortality associated with delayed diagnosis.

\section{Conclusion}

The advent of COVID-19 in the Spring of 2020 disrupted screening mammogram schedules for many. The measure of this impact and the overall effect in a largely rural West Central Illinois region has been elucidated in this study. The findings reveal that there was a significant reduction in uptake during the pandemic restriction period. However, increased uptake during the rest of the year effectively mitigated 
this reduction to such an extent that there was no statistically significant downturn compared to each of the previous two years. Presumably, a rising trend in annual uptake noted in preceding years could have continued without the COVID-19 events.

\section{References}

1. DeSantis, C.E., Ma, J., Gaudet, M.M., Newman, L.A., Miller, K.D., Goding Sauer, A., Jemal, A. and Siegel, R.L. (2019), Breast cancer statistics, 2019. CA A Cancer J Clin, 69: 438451. https://doi.org/10.3322/caac. 21583

2. SEER*Explorer: An interactive website for SEER cancer statistics [Internet]. Surveillance Research Program, National Cancer Institute. [Cited 2021 April 15]. Available from https://seer.cancer.gov/explorer/.

3. American Cancer Society. Cancer Facts \& Figures 2021. Atlanta: American Cancer Society; 2021.

4. Coldman A, Phillips N, Wilson C, et al. Pan-Canadian study of mammography screening and mortality from breast cancer [published correction appears in J Natl Cancer Inst. 2015 Jan;107(1):dju404 doi:10.1093/jnci/dju404]. J Nat/ Cancer Inst. 2014;106(11):dju261. Published 2014 Oct 1. doi:10.1093/jnci/dju261

5. Paci E, Broeders M, Hofvind S, Puliti D, Duffy SW; EUROSCREEN Working Group. European breast cancer service screening outcomes: a first balance sheet of the benefits and harms. Cancer Epidemiol Biomarkers Prev. 2014;23(7):1159-1163. doi:10.1158/1055-9965.EPI-13-0320

6. Tabár L, Dean PB, Chen TH, et al. The incidence of fatal breast cancer measures the increased effectiveness of therapy in women participating in mammography screening. Cancer. 2019;125(4):515-523. doi:10.1002/cncr.31840

7. American Cancer Society. Breast Cancer Facts \& Figures 2019-2020. Atlanta: American Cancer Society, Inc. 2019.

8. Hall I, Tangka F, Sabatino S, et al. Patterns and Trends in Cancer Screening in the United States. Prev Chronic Dis. 2018;15:170465. Doi:10.5888/pcd15.170465

9. Nyante S, Benefield T, Kuzmiak C et al. Population-level impact of coronavirus disease 2019 on breast cancer screening and diagnostic procedures. Cancer. 2021;127(12):21112121. doi.org/10.1002/cncr.33460

10. Trump White House. 15 Days to Slow the Spread. March 16, 2020. Available at: https://trumpwhitehouse.archives.gov/articles/15-days-slow-spread/. Assessed June 22, 2021

11. Stempniak M. Radiologists urged to reschedule all nonurgent imaging in wake of COVID-19's spread. Radiology Business. March 17, 2020. https://www.radiologybusiness.com/topics/economics/radiologists-nonurgent-imagingcoronavirus-x-ray-covid-19. Assessed June 22, 2021

12. Stempniak M. American Cancer Society joins chorus advocating for delay of routine radiology screenings. March 20, 2020. https://www.radiologybusiness.com/topics/leadership- 
workforce/american-cancer-society-delay-routine-radiology-screening. Assessed June 22, 2021

13. Ambulatory Surgery Center Association. IDPH recommended cancelling of all elective surgeries and procedures. March 17, 2020. https://www.ascassociation.org/asca/resourcecenter/latestnewsresourcecenter/covid19/covid-19-state. Assessed June 22, 2021.

14. Illinois Department of Public Health. COVID-19 - Elective Surgical Procedure Guidance. May 11, 2020. https://www.dph.illinois.gov/topics-services/diseases-and-conditions/diseases-a-zlist/coronavirus/health-care-providers/elective-procedures-guidance. Assessed June 22, 2021.

15. Duszak R, Maze J, Sessa C, et al. Characteristics of COVID-19 Community Practice Declines in Noninvasive Diagnostic Imaging Professional Work. JACR. 2020;17(11):1453-1459. Doi: 10.1016/j.jacr.2020.06.031

16. Sprague BL, O'Meara ES, Lee Cl, Lee JM, Henderson LM, Buist DS, Alsheik N, Macarol T, Perry H, Tosteson AN, Onega T. Prioritizing breast imaging services during the COVID pandemic: A survey of breast imaging facilities within the Breast Cancer Surveillance Consortium. Preventive Medicine. 2021 Oct 1;151:106540.

17. Parikh K, Ramaiya N, Kikano E, et al. COVID-19 Pandemic Impact on Decreased Imaging Utilization: A Single Institutional Experience. Academic Radiology. 2020;27(9):1204-1213.

Doi: 10.1016/j.acra.2020.06.024

18. Sprague, BL, Lowry KP, Miglioretti DL, Alsheik N, Bowles EJ, Tosteson AN, et al. Changes in Mammography Use by Women's Characteristics During the First 5 Months of the COVID-19 Pandemic. Journal of the National Cancer Institute, 2021;113(9):1161-1167. Doi: 10.1093/jnci/djab04

19. Freer P. The Impact of the COVID-19 Pandemic on Breast Imaging. Radiologic Clinics. 2020;59(1):111. Doi:10.1016/j.rcl.2020.09.008.

20. Illinois Area Health Education Centers. West Central AHEC. https://ilahec.uic.edu/regionalcenters/wc/. Assessed on January 23, 2021.

21. Wang F, McLafferty S, Escamilla V, Luo L. Late-stage breast cancer diagnosis and health care access in Illinois. The Professional Geographer. 2008 Jan 1;60(1):54-69.

22. U.S. Census Bureau QuickFacts: Illinois. https://www.census.gov/quickfacts/geo/chart/IL/POP010220. Assessed June 22, 2021.

23. Miller MM, Meneveau MO, Rochman CM, et al. Impact of the COVID-19 pandemic on breast cancer screening volumes and patient screening behaviors. Breast Cancer Res Treat. 2021;189(1):237-246. doi:10.1007/s10549-021-06252-1

\section{Tables}




\begin{tabular}{|c|c|c|c|c|}
\hline Row Labels & $\begin{array}{l}\text { Sum of Measure } \\
\text { Values }\end{array}$ & $\begin{array}{l}\text { Cummulative } \\
\text { frequency }\end{array}$ & $\begin{array}{l}\text { \% of } \\
\text { total }\end{array}$ & $\begin{array}{l}\text { cummulative } \\
\%\end{array}$ \\
\hline $\begin{array}{l}17161 \text { - ROCK ISLAND } \\
\text { COUNTY, IL }\end{array}$ & 35763 & 35763 & $35 \%$ & $34.7 \%$ \\
\hline $\begin{array}{l}17001 \text { - ADAMS COUNTY, } \\
\text { IL }\end{array}$ & 13247 & 49010 & $13 \%$ & $47.6 \%$ \\
\hline $\begin{array}{l}17095 \text { - KNOX COUNTY, } \\
\text { IL }\end{array}$ & 11287 & 60297 & $11 \%$ & $58.5 \%$ \\
\hline $\begin{array}{l}17057 \text { - FULTON } \\
\text { COUNTY, IL }\end{array}$ & 8621 & 68918 & $8 \%$ & $66.9 \%$ \\
\hline $\begin{array}{l}17109 \text { - MCDONOUGH } \\
\text { COUNTY, IL }\end{array}$ & 6105 & 75023 & $6 \%$ & $72.8 \%$ \\
\hline $\begin{array}{l}17131 \text { - MERCER } \\
\text { COUNTY, IL }\end{array}$ & 4045 & 79068 & $4 \%$ & $76.8 \%$ \\
\hline $\begin{array}{l}\text { 17125 - MASON COUNTY, } \\
\text { IL }\end{array}$ & 3910 & 82978 & $4 \%$ & $80.6 \%$ \\
\hline $\begin{array}{l}\text { 17187 - WARREN } \\
\text { COUNTY, IL }\end{array}$ & 3884 & 86862 & $4 \%$ & $84.3 \%$ \\
\hline $\begin{array}{l}17067 \text { - HANCOCK } \\
\text { COUNTY, IL }\end{array}$ & 3410 & 90272 & $3 \%$ & $87.7 \%$ \\
\hline $\begin{array}{l}17061 \text { - GREENE } \\
\text { COUNTY, IL }\end{array}$ & 3060 & 93332 & $3 \%$ & $90.6 \%$ \\
\hline $\begin{array}{l}17017 \text { - CASS COUNTY, } \\
\text { IL }\end{array}$ & 2598 & 95930 & $3 \%$ & $93.1 \%$ \\
\hline 17149 - PIKE COUNTY, IL & 2003 & 97933 & $2 \%$ & $95.1 \%$ \\
\hline $\begin{array}{l}17169 \text { - SCHUYLER } \\
\text { COUNTY, IL }\end{array}$ & 1485 & 99418 & $1 \%$ & $96.5 \%$ \\
\hline $\begin{array}{l}17171 \text { - SCOTT COUNTY, } \\
\text { IL }\end{array}$ & 1127 & 100545 & $1 \%$ & $97.6 \%$ \\
\hline $\begin{array}{l}17013 \text { - CALHOUN } \\
\text { COUNTY, IL }\end{array}$ & 931 & 101476 & $1 \%$ & $98.5 \%$ \\
\hline $\begin{array}{l}17009 \text { - BROWN COUNTY, } \\
\text { IL }\end{array}$ & 825 & 102301 & $1 \%$ & $99.3 \%$ \\
\hline $\begin{array}{l}17071 \text { - HENDERSON } \\
\text { COUNTY, IL }\end{array}$ & 686 & 102987 & $1 \%$ & $100.0 \%$ \\
\hline Grand Total & 102987 & & $100 \%$ & \\
\hline
\end{tabular}

Table 1. Total screening mammogram uptake in West Central Illinois January 2018December 2020 


\begin{tabular}{|c|c|c|c|c|c|c|}
\hline Year/Month & 2018 & 2019 & 2020 & $\begin{array}{l}\text { Monthly } \\
\text { Average } \\
\text { 2018-2019 } \\
\text { (Base } \\
\text { year) }\end{array}$ & $\begin{array}{c}\text { Percentage } \\
\text { Difference } \\
\text { 2020/Base year } \\
(\%)\end{array}$ & $\begin{array}{l}\text { Cumulative } \\
\text { difference } \\
\text { 2020/Base year }\end{array}$ \\
\hline January & 2700 & 2488 & 2921 & 2594 & $113 \%$ & 327 \\
\hline February & 2581 & 2652 & 2518 & 2617 & $96 \%$ & 229 \\
\hline March & 2965 & 2943 & 1649 & 2954 & $56 \%$ & -1077 \\
\hline April & 2933 & 3057 & 56 & 2995 & $2 \%$ & -4016 \\
\hline May & 3000 & 3021 & 1490 & 3011 & $49 \%$ & -5536 \\
\hline June & 2916 & 2823 & 3085 & 2870 & $108 \%$ & -5321 \\
\hline July & 2897 & 3135 & 3131 & 3016 & $104 \%$ & -5206 \\
\hline August & 3228 & 3079 & 2972 & 3154 & $94 \%$ & -5387 \\
\hline September & 2752 & 2979 & 3008 & 2866 & $105 \%$ & -5245 \\
\hline October & 3731 & 3728 & 3590 & 3730 & $96 \%$ & -5384 \\
\hline November & 3256 & 3187 & 3084 & 3222 & $96 \%$ & -5522 \\
\hline \multirow{2}{*}{ December } & 3083 & 3215 & 3134 & 3149 & $100 \%$ & -5537 \\
\hline & 36042 & 36307 & 30638 & 36175 & $84.7 \%$ & \\
\hline
\end{tabular}

Table 2. Annual screening mammogram uptake in West Central Illinois 2018-2020

Table 3

Paired Samples Effect Sizes

\begin{tabular}{|c|c|c|c|c|c|c|}
\hline & \multirow[b]{2}{*}{ Standardiser } & \multirow{2}{*}{$\begin{array}{l}\text { Point } \\
\text { Estimate }\end{array}$} & \multicolumn{2}{|c|}{$\begin{array}{l}\text { 95\% Confidence } \\
\text { Interval }\end{array}$} \\
\hline & & & & & Lower & Upper \\
\hline Pair & Uptake in 2018 - uptake & Cohen's d & 961.757 & .468 & -.139 & 1.057 \\
\hline & in 2020 & $\begin{array}{l}\text { Hedges' } \\
\text { correction }\end{array}$ & 996.174 & .452 & -.134 & 1.020 \\
\hline Pair & uptake in 2019 - uptake & Cohen's d & 984.834 & .480 & -.129 & 1.070 \\
\hline & in 2020 & $\begin{array}{l}\text { Hedges' } \\
\text { correction }\end{array}$ & 1020.077 & .463 & -.125 & 1.033 \\
\hline Pair & Uptake in 2018 - uptake & Cohen's d & 141.951 & -.156 & -.722 & .417 \\
\hline & in 2019 & $\begin{array}{l}\text { Hedges' } \\
\text { correction }\end{array}$ & 147.031 & -.150 & -.697 & .403 \\
\hline
\end{tabular}

a. The denominator used in estimating the effect sizes.

Cohen's d uses the sample standard deviation of the mean difference.

Hedges' correction uses the sample standard deviation of the mean difference, plus a correction factor.

\section{Figures}




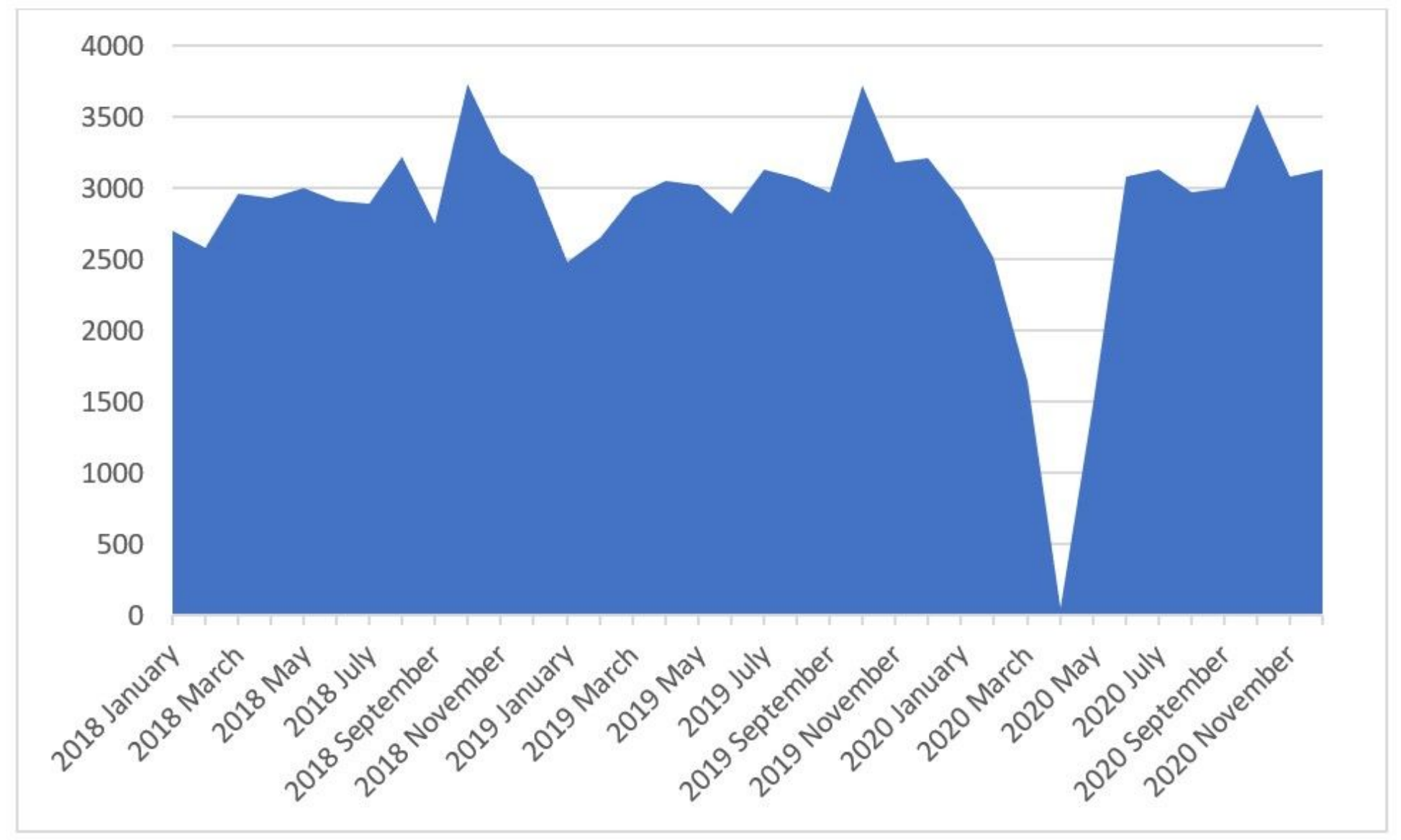

Figure 1

Graph showing the relative changes in screening mammogram uptake per month (2018-2020). 


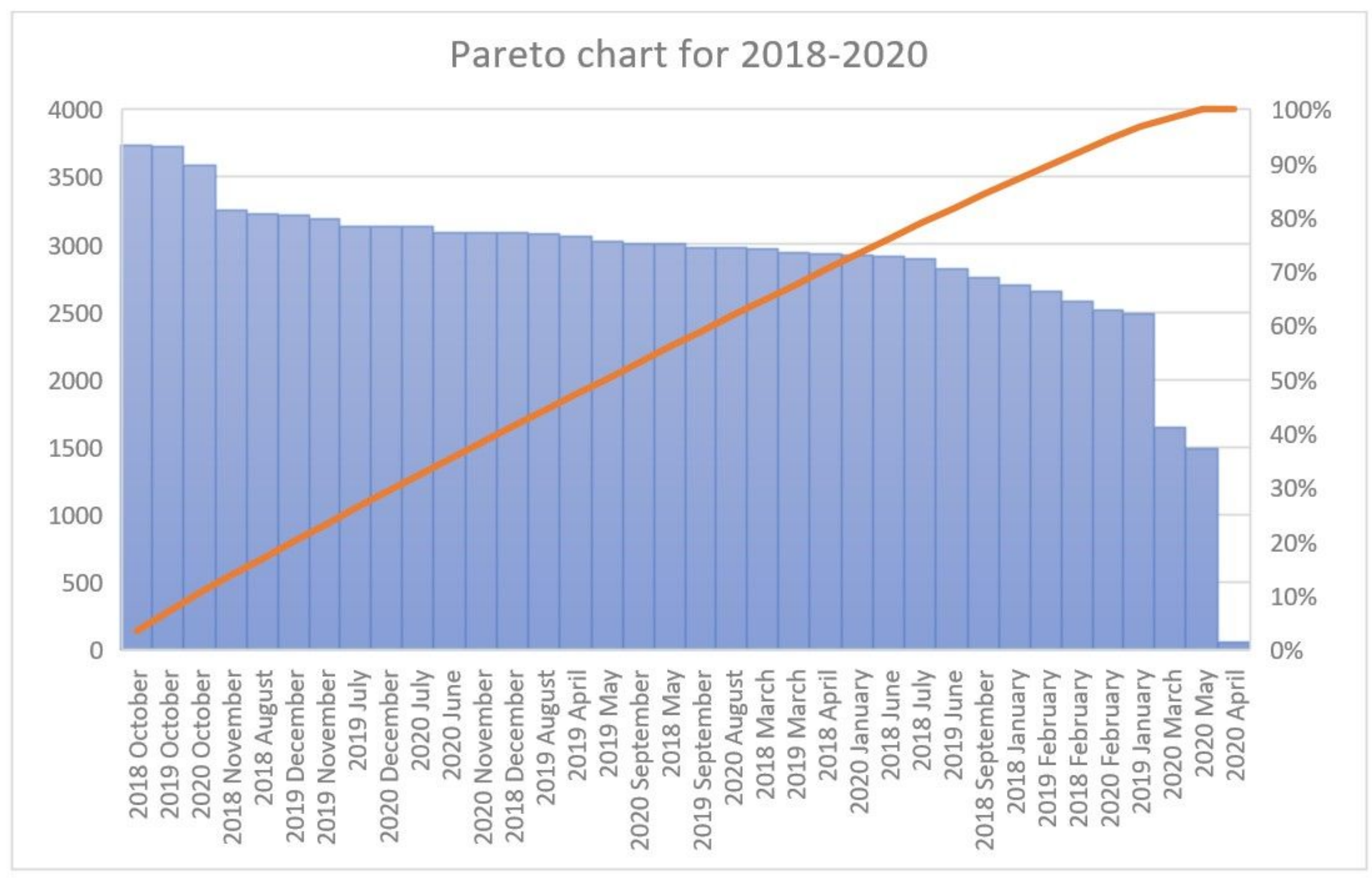

Figure 2

Chart showing monthly trends within the 2018, 2019, and 2020. 


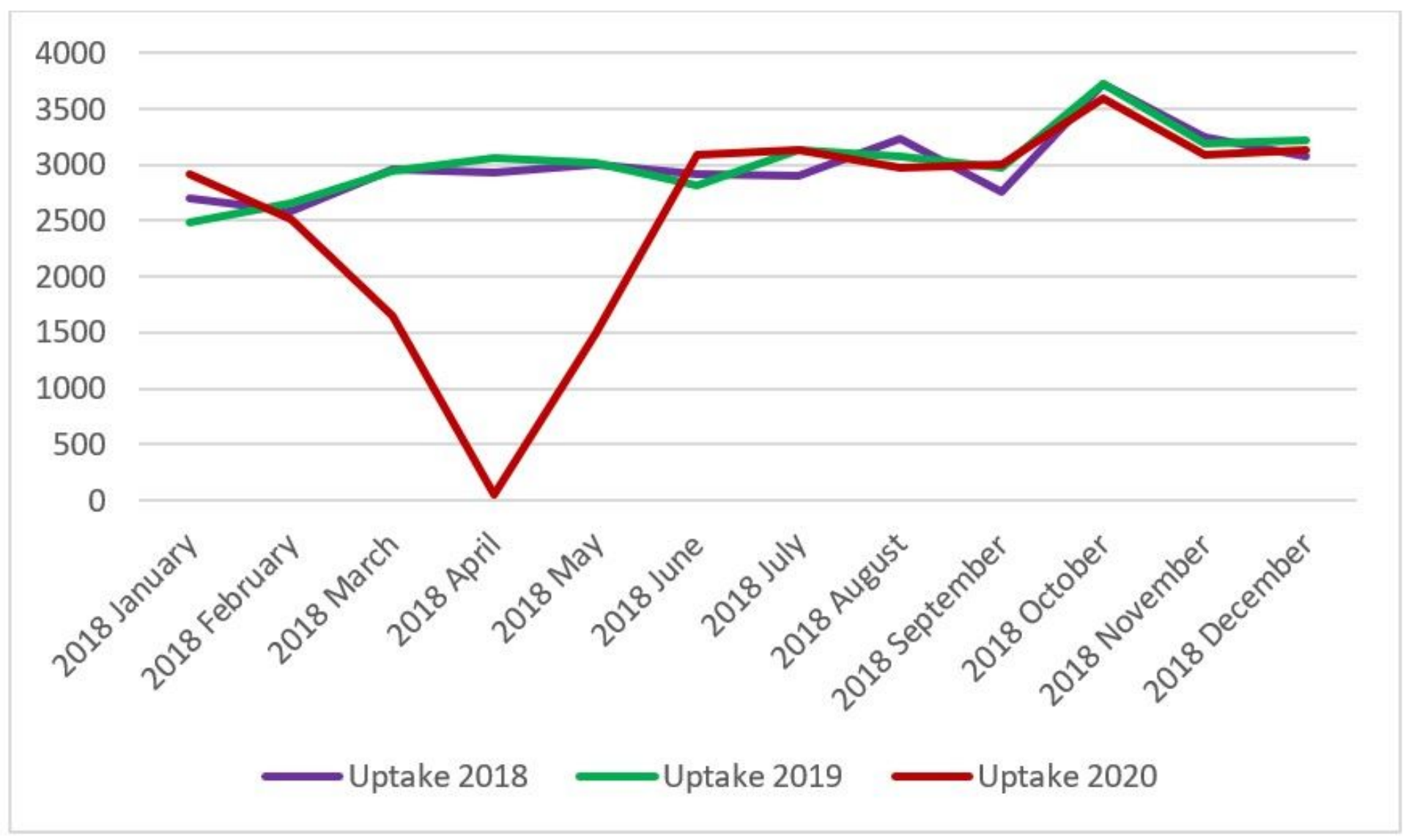

\section{Figure 3}

Trend lines comparing screening mammogram uptake in 2018, 2019 and 2020. 


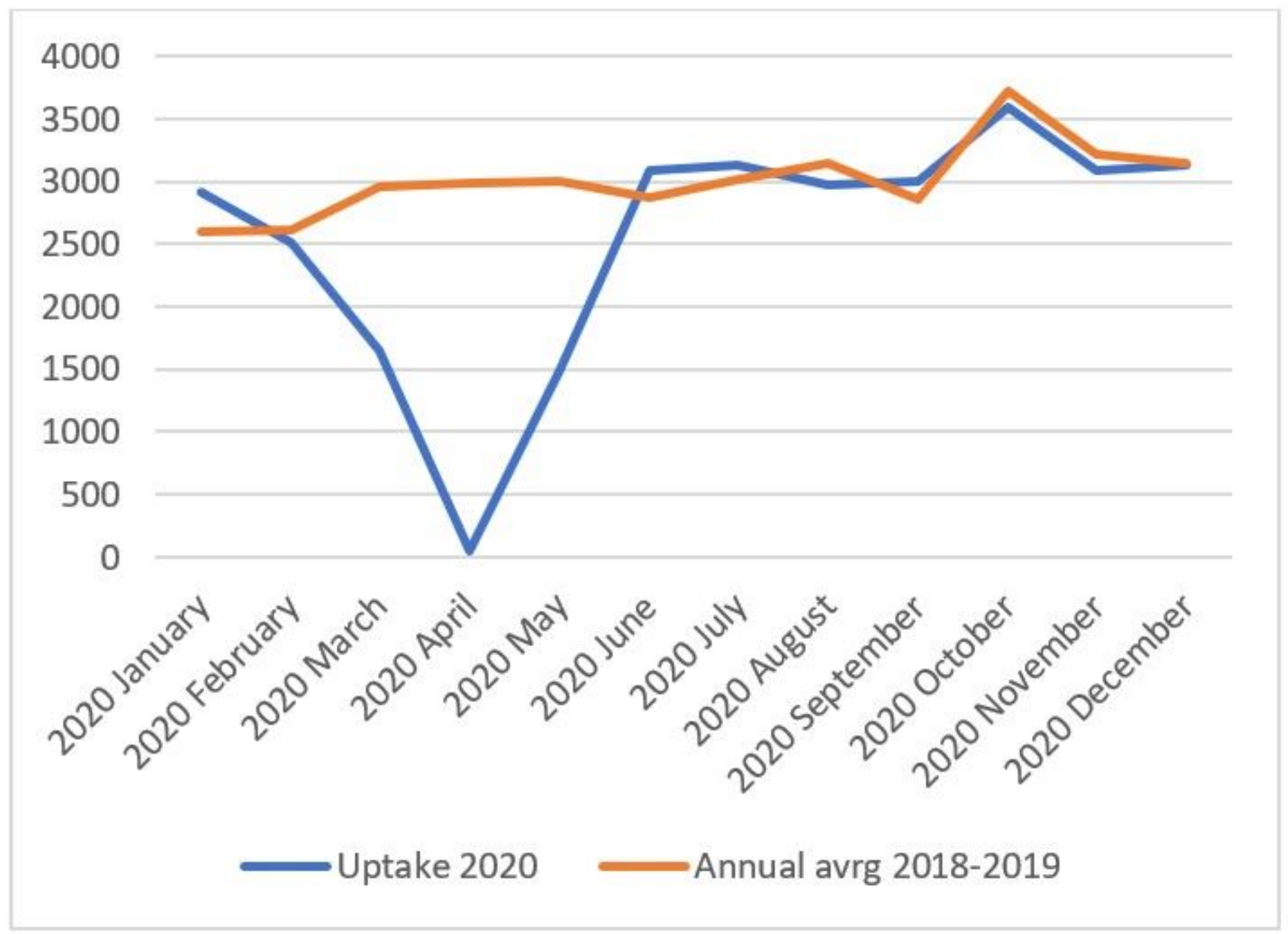

\section{Figure 4}

Trending lines comparing screening mammogram uptake between 2020 and the calculate monthly mean for previous years. 